\title{
Article \\ Extracellular Matrix Behaviour in Masseter Muscle of Patients Affected by Unilateral Posterior Crossbite: An Immunofluorescence Study
}

\author{
Giovanna Vermiglio ${ }^{1}\left(\mathbb{D}\right.$, Antonio Centofanti ${ }^{1, *} \mathbb{D}$, Maria Grazia Piancino ${ }^{2}$, Maria Chiara Malandrino ${ }^{3}$, \\ Michele Runci Anastasi ${ }^{4}$, Giacomo Picciolo ${ }^{1}$ and Giuseppina Cutroneo ${ }^{1}$ \\ 1 Department of Biomedical and Dental Science and Morphofunctional Imaging, University of Messina, \\ 98100 Messina, Italy; giovanna.vermiglio1@unime.it (G.V.); giacomo.picciolo@unime.it (G.P.); \\ gcutroneo@unime.it (C.G.) \\ 2 Department of Surgical Sciences, Dental School, Orthodontics, University of Turin, 10125 Turin, Italy; \\ mariagrazia.piancino@unito.it \\ 3 School of Maxillofacial Surgery, University of Turin, 10125 Turin, Italy; mariachiara.malandrino@unito.it \\ 4 I.R.C.C.S (Istituto di Ricovero e Cura a Carattere Scientifico) Centro Neurolesi "Bonino-Pulejo", \\ 98100 Messina, Italy; michele.runci@irccsme.it \\ * Correspondence: centofantia@unime.it
}

Citation: Vermiglio, G.; Centofanti, A.; Piancino, M.G.; Malandrino, M.C.; Runci Anastasi, M.; Picciolo, G.; Cutroneo, G. Extracellular Matrix Behaviour in Masseter Muscle of Patients Affected by Unilateral Posterior Crossbite: An Immunofluorescence Study. Appl. Sci. 2021, 11, 4649. https://doi.org/ 10.3390/app11104649

Academic Editors: Carla Loreto and Rosario Caltabiano

Received: 30 April 2021

Accepted: 14 May 2021

Published: 19 May 2021

Publisher's Note: MDPI stays neutral with regard to jurisdictional claims in published maps and institutional affiliations.

Copyright: (c) 2021 by the authors. Licensee MDPI, Basel, Switzerland. This article is an open access article distributed under the terms and conditions of the Creative Commons Attribution (CC BY) license (https:/ / creativecommons.org/licenses/by/ $4.0 /)$.
Abstract: Unilateral posterior crossbite is a malocclusion disease that involves morpho-functional characteristics of masseter muscle; a normal or increased activity of contralateral muscle and a reduced activity of the ipsilateral muscle during unilateral crossbite have been shown. Since the extracellular matrix plays a key role in in mechano-transduction of transmitting forces during muscle contraction, the aim of the present study was to analyse the behaviour of extracellular matrix in this type of malocclusion through immunofluorescence reactions against laminin, collagen IV, MMP-2 and MMP-9. Our results show an increased expression of Laminin, Collagen IV, and MMP-9 in the contralateral side if compared to the ipsilateral side. No differences have been found in MMP-2 expression between contralateral and ipsilateral muscles. Since the increased expression of Laminin, Collagen IV and MMP-9 is associated with muscle hypertrophy and MMP-2 is associated with muscle atrophy, our results support the existence of a hypertrophic response of contralateral muscle during unilateral posterior crossbite that probably aims to compensate the altered function of the ipsilateral one.

Keywords: masseter muscle; unilateral crossbite; extracellular matrix; immunofluorescence

\section{Introduction}

Unilateral posterior crossbite is a widespread malocclusion where it is possible to observe an inverse relationship of the upper and lower buccal dental cusps on one side only of the dental arch [1,2]. Altered kinematics of the mandible-reverse chewing cycles-have been observed when chewing on the affected side; that would depend on the fact that the masseter of the crossbite side is less active with respect to the contralateral and to controls $[3,4]$.

In recent years, several studies have observed morphological features of masticatory muscle during unilateral posterior crossbite [5,6]. Most of them focused on the behaviour of muscle fibres showing different changes in protein expression and size between the ipsilateral and the contralateral muscles. In detail, it has been shown that the contralateral muscle presents an increased expression of sarcoglycans and integrins, which are proteins that usually play a key role in sarcolemma stabilisation during muscle activity [7-10]. Moreover, the contralateral side has a greater number of myonuclei and satellite cells then the ipsilateral side [11]. 
All these data have suggested that the ipsilateral muscle undergoes hypotrophy/atrophy while the contralateral muscle undergoes hypertrophy, probably in order to compensate the low activity of ipsilateral muscle [11,12].

Although not much information about extracellular matrix behaviour during unilateral posterior crossbite exists, Guerra et al. [13] have shown an increment in extracellular matrix remodelling in contralateral side on a rat model.

Interactions between muscle fibres and extracellular matrix are fundamental in mechanotransduction of transmitting forces and also during muscular development [14-17]. On this basis and since important morphological changes have been already demonstrated during unilateral posterior crossbite, the aim of the present study was to analyse the behaviour of extracellular matrix in this type of malocclusion through immunofluorescence reactions against laminin, collagen IV, MMP-2, and MMP-9.

\section{Materials and Methods}

\subsection{Patients and Samples}

Ten patients, 5 male and 5 females, $22.5 \pm 7$ years old (mean \pm standard deviation), with severe skeletal class III (point-Nasion-B point angle $=-2.6 \pm 1.5$ mean \pm standard deviation) and unilateral posterior crossbites have been randomly recruited to participate in this study. Patients showed left (6 patients) and right (4 patients) unilateral, posterior crossbite involving the molar teeth; five of them were open bite and five were deep bite. Inclusion criteria were as follows: skeletal and dental severe, surgical class III; posterior crossbite and presence of all teeth (with the exception of the third molars). Exclusion criteria were as follows: the presence of previous orthodontic therapy; erupting teeth; caries; dental pain; the presence of fixed or removable dental prosthesis; periodontal disease; presence of craniofacial syndromes or clefts; presence of inflammatory or neuromuscular disorders.

The patients received bilateral sagittal split (BSSO) to reduce the mandibular excess. Biopsies of masseter muscle have been withdrawn from left and right sides for each patient. The investigation conformed with guidelines established by the University Internal Review Board for use of Human Subjects and with the principles outlined in the Helsinki Declaration of 1975. Ethics committee approval: "Morphological and molecular evaluation of the masseter muscle in orthognathic surgical patients" approved on 18 June 2018 protocol n.0063261, document number CS2/372 of "Comitato Etico Interaziendale A.O.U. Città della Salute e della Scienza di Torino-A.O. Ordine Mauriziano-A.S.L. Città di Torino".

\subsection{Immunofluorescence}

The muscle biopsies were extracted and were fixed in $3 \%$ paraformaldehyde in 0.2 $\mathrm{mol} / \mathrm{L}$ phosphate buffer, $\mathrm{pH}$ 7.4. After numerous rinses in $0.2 \mathrm{~mol} / \mathrm{L}$ phosphate buffer and phosphate buffered saline, $0.2 \mathrm{~mol} / \mathrm{L}$, pH 7.6 with $0.9 \% \mathrm{NaCl}(\mathrm{PBS})$, they were infiltrated with $12 \%$ and $18 \%$ saccharose and then they were frozen in liquid nitrogen and were stored at $-20{ }^{\circ} \mathrm{C}$. By cryotomy, specimens have been cut in $30 \mu \mathrm{m}$ sections collected on glass slides coated with $0.5 \%$ gelatine and $0.005 \%$ chromium potassium sulphate. Four series of single localisation reactions have been performed: (1) single localisation for Lamin, Collagen IV, MMP-2, and MMP-9 [18-20].

To block non-specific sites and to make the membranes permeable, the sections were pre-incubated with $1 \%$ bovine serum albumin (BSA) and $0.3 \%$ Triton X-100 in PBS at room temperature for $15 \mathrm{~min}$. Finally, the sections were incubated with primary antibodies at room temperature for $2 \mathrm{~h}$. The following primary antibodies were used: goat polyclonal anti Laminin (diluted 1:250, Sigma-Aldrich, St. Louise, Missouri, USA); goat polyclonal anti Collagen IV (diluted 1:250, Sigma-Aldrich); goat polyclonal anti MMP-2 (diluted 1:150, Novus Biologicals); goat polyclonal anti MMP-9 (diluted 1:150, Novus Biologicals, CO, USA).

Laminin and collagen IV primary antibodies were demonstrated with Texas-Redconjugated IgG anti goat (1:100 dilution; Jackson Immuno-Research Lab., West Grove, PA, USA); MMP-2 and MMP-9 were demonstrated with FITC-conjugated IgG anti goat (1:100 
dilution; Jackson Immuno-Research Lab., West Grove, PA, USA). The fluorochrome was applied for $1 \mathrm{~h}$ at room temperature. Finally, the slides were washes in PBS and sealed with mounting medium.

\subsection{Confocal Microscopy}

Samples were observed with a Zeiss LSM 510 confocal microscope equipped with Argon laser (458 nm and $488 \mathrm{~nm}$ ) and two HeNe laser (543 nm and $633 \mathrm{~nm}$ ) [21]. All images were digitised at a resolution of 8 bits into an array of $2048 \times 2048$ pixels. Optical sections of fluorescence specimens were obtained at $488 \mathrm{~nm}$, at $62 / \mathrm{s}$ scanning shipped with up to 8 repetitions on average. The pinhole was set for optimal resolution. Contrast and brightness were established by examining the most brightly labelled pixels and choosing settings that allowed clear visualisation of structural details while keeping the highest pixel intensities near 200. Digital images were cropped and figure montages prepared using Adobe Photoshop 7.0.

Using the function "Histo" of confocal laser microscope we measured in all patients" muscle samples the intensity of fluorescence staining pattern for each tested protein in 10 fibres of ipsilateral and 10 fibres of contralateral muscle. The means have been inserted in a graphic.

\subsection{Statistical Analysis}

We used the means of each tested proteins obtained by the "Histo" function of confocal laser microscope to perform a T-Student test to verify if a statistically significant difference of protein expression exists between contralateral and ipsilateral muscles.

\section{Results and Discussion}

Immunofluorescence results showed that during unilateral posterior crossbite the contralateral muscle, if compared to the ipsilateral one, has: (1) an increased expression of Laminin; (2) increased expression of Collagen IV; (3) increased expression of MMP-9; and (4) the same expression of MMP-2.

Laminin is an extracellular matrix protein that interacts with integrins and dystrophin glycoprotein complex representing an important interactor between muscle fibres cytoskeleton and extracellular matrix [22,23]. Our data show the typical Laminin staining pattern around the muscle fibres, at basal lamina level (Figure 1). Moreover, results show that this protein is more expressed in the contralateral muscle fibres then ipsilateral ones (Figure 1A,B), and this difference is statistically significant as shown in Figure 5. That is in accordance with our previous results showing an increased sarcoglycans and integrins expression in the contralateral side if compared to the ipsilateral side $[7,8]$. From this, it is possible to speculate that in the contralateral side the increased of muscle proteins determines in turns the increase of their extracellular matrix interactor.

Muscle hypertrophy is often accompanied by increased collagen deposition $[24,25]$. The basement membrane collagens directly surround muscle fibres and assist in the transfer of lateral and longitudinal transmission of force in muscle [24]. Our results show an increase in collagen IV expression in the contralateral muscle if compared to the ipsilateral one (Figure 2), and this difference is statistically significant as shown in Figure 5. That is in accordance with the evidence of hypertrophic response of contralateral muscle. In the ipsilateral side it is possible to observe collagen IV staining pattern. This result suggest that the ipsilateral muscle is not under a manifest hypotrophy/atrophy condition. 


\section{Laminin}
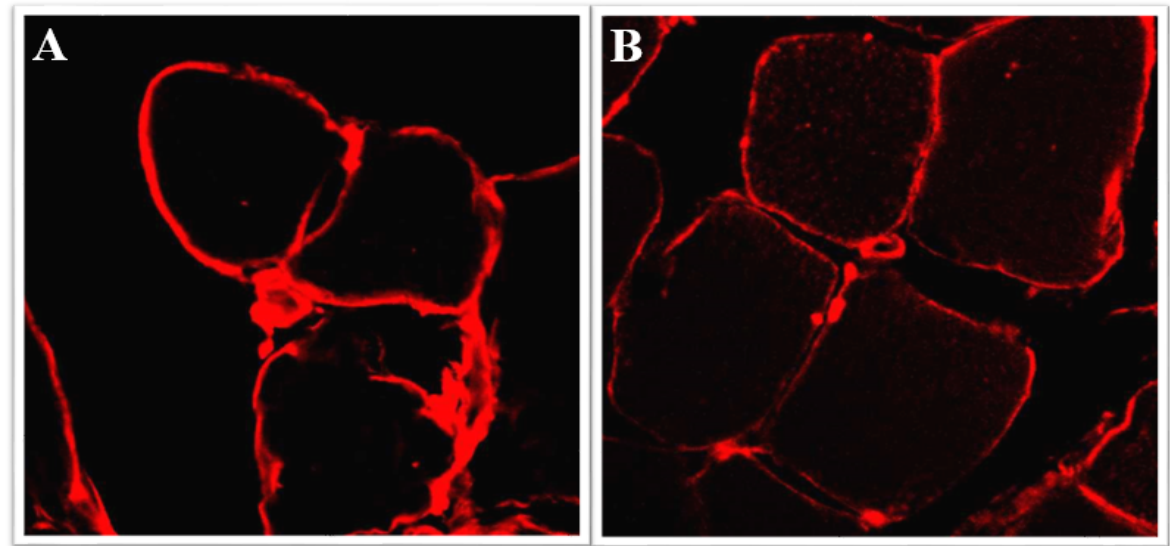

Figure 1. Immunofluorescence reactions anti Laminin (red fluorescence) in contralateral (A) and ipsilateral (B) masseter muscle of patients affected by unilateral posterior crossbite. The fluorescence pattern of laminin is mainly located around the muscle fibres, at basal lamina level. The contralateral muscle seems to show a higher Laminin staining pattern if compared to the ipsilateral. $p$-value $<0.05$.

\section{Collagen IV}
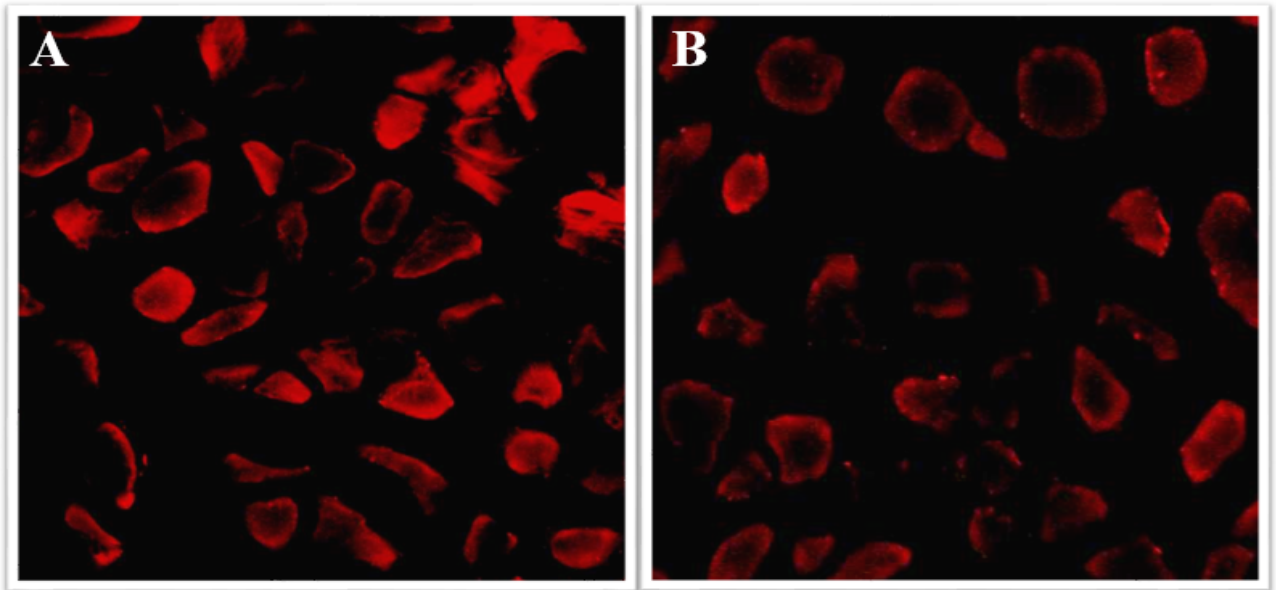

Figure 2. Immunofluorescence reactions anti collagen IV (red fluorescence) in contralateral (A) and ipsilateral (B) masseter muscle of patients affected by unilateral posterior crossbite. The fluorescence pattern of collagen IV seems to be a higher fluorescence pattern if compared to the ipsilateral one. $p$-value $<0.05$.

Changes in the basement membrane collagens were accompanied by generally similar changes in the gelatinases MMP2 and MMP9 [24,25]. Metalloproteinases are proteins with enzymatic activity that play a key role in selective proteolysis of ECM components [26,27]. MMP2 and MMP9 are the typical MMPs of skeletal muscle and are involved in the degradation of collagen IV [28].

In the contralateral muscle it is possible to observe a MMP2 and MMP9 staining pattern. These metalloproteinases are both around and within muscle fibres. In the ipsilateral side the MMP2 expression is similar to the contralateral side (Figure 3) and this difference is not statistically significant as shown in Figure 5; the MMP9 staining pattern is weak if compared to the contralateral side (Figure 4), and this difference is statistically significant as shown in Figure 5. 
MMP-2
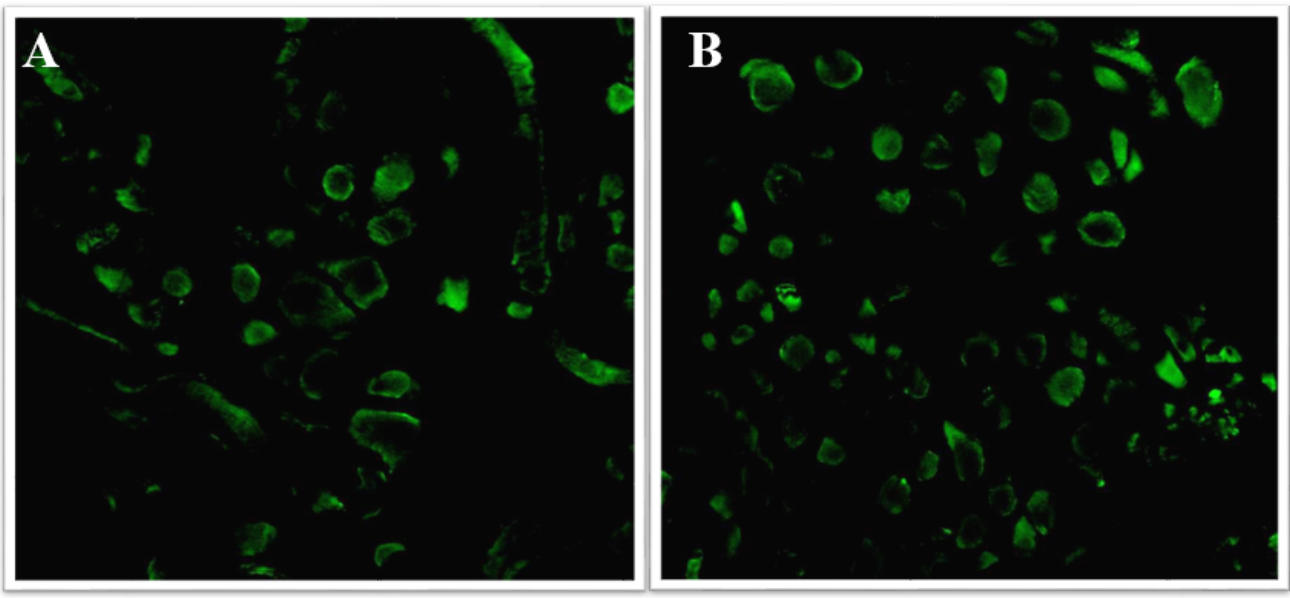

Figure 3. Immunofluorescence reactions anti MMP-2 (green fluorescence) in contralateral (A) and ipsilateral (B) masseter muscle of patients affected by unilateral posterior crossbite. There is no difference in MMP-2 staining pattern between contralateral and ipsilateral muscles. $p$-value $>0.05$.

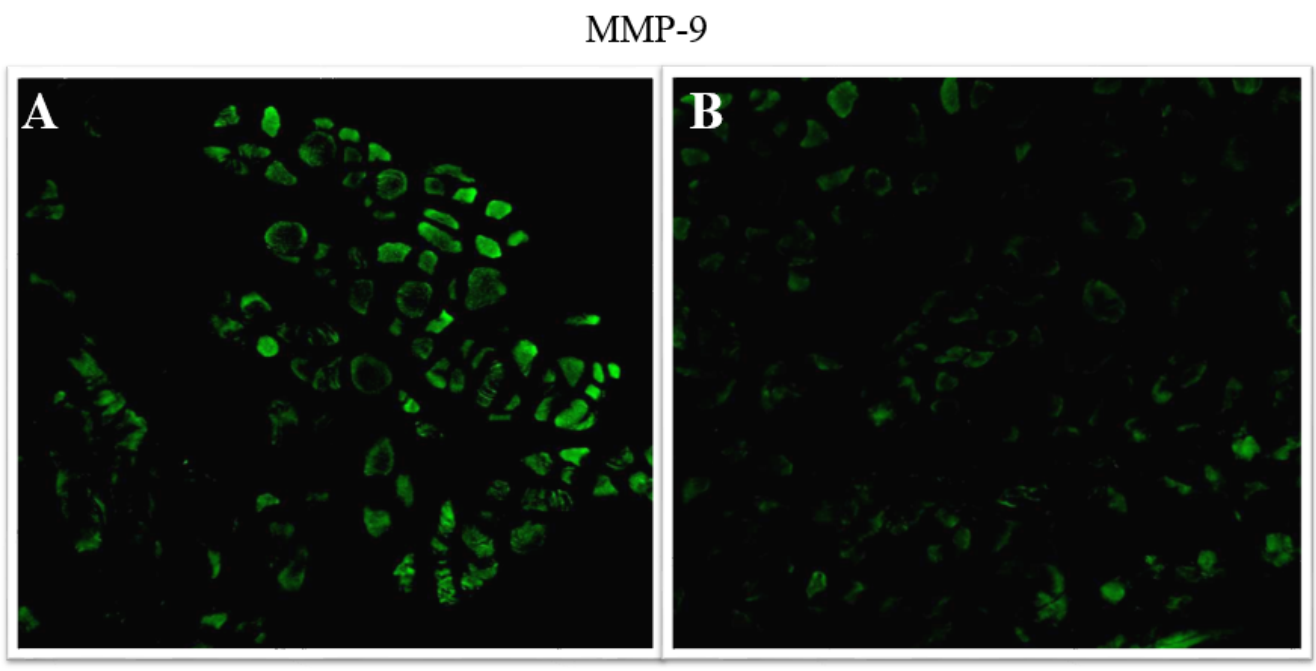

Figure 4. Immunofluorescence reactions anti MMP-9 (green fluorescence) in contralateral (A) and ipsilateral (B) masseter muscle of patients affected by unilateral posterior crossbite. The fluorescence pattern of MMP-9 is higher in the contralateral masseter muscle if compared to the fluorescence pattern in the ipsilateral muscle. $p$-value $<0.05$.

MMP2 is always expressed in skeletal muscle and does not undergo particular regulation processes; MMP9, instead, has been found increased in response to high workload [29]. Studies have also demonstrated that high levels of MMP9 leads to hypertrophy and to an increased muscle strength. Our results, showing a higher expression of MMP9 in the contralateral muscle are in accordance with evidence of hypertrophic response of contralateral masseter muscle.

Reduction in muscle protein synthesis and increased muscle degradation seem to be correlated to the loss of muscle mass in muscle atrophy. It has been hypothesised that the intracellular MMP-2 form can degrades intracellular matrix in some pathological conditions [30]. Moreover, it has been speculated that the MMP-2 could play an important role during muscle atrophy [31-33]. Our results, showing the same MMP2 expression both in contralateral and ipsilateral side, do not allow us to speculate that in the ipsilateral side hypotrophic/atrophic events take place. 


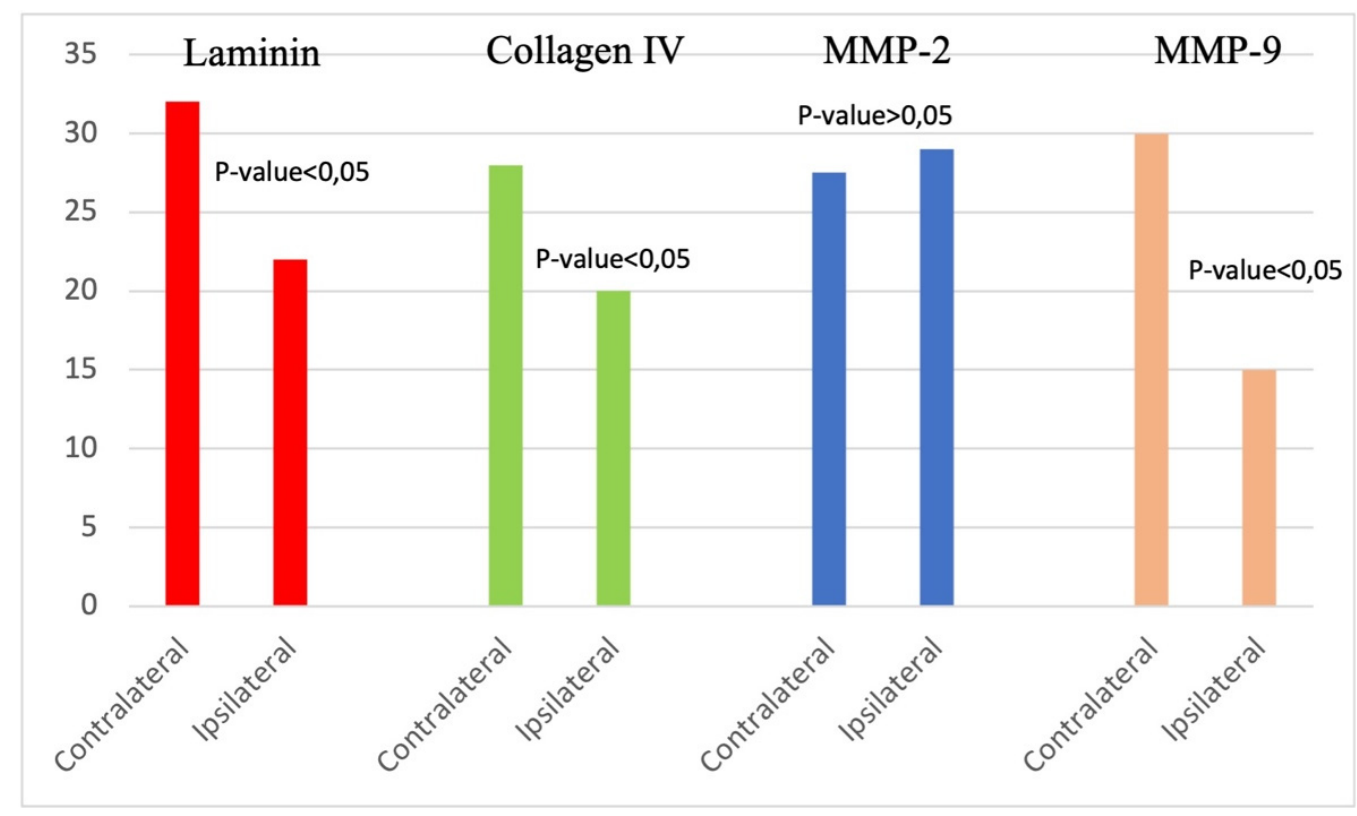

Figure 5. The graphic shows the means of fluorescence intensity for each tested proteins both in the contralateral and the ipsilateral muscles. The means were obtained by the function "Histo" of confocal laser microscope. Laminin, Collagen IV, and MMP-9 are more expressed in the contralateral muscle than in the ipsilateral one. For the MMP-2 the values for contralateral and ipsilateral muscles are close to each other.

\section{Conclusions}

Our data show that in unilateral posterior crossbite, the contralateral Masseter muscle exhibits an increased expression of collagen IV, laminin, and MMP9 if compared to the ipsilateral one, although the ipsilateral muscle shows the expression of all tested proteins. That led us to hypothesise that the observed increased expression in contralateral side could be correlated to a hypertrophic response of this muscle in accordance with our previous results. The ECM behaviour of ipsilateral side, instead, is not representative of a hypotrophic/atrophic response. This suggest that during unilateral posterior crossbite, the first response is represented by hypertrophy of contralateral muscle, probably in order to balance the low activity of the affected side. However, we cannot exclude the possibility that the ipsilateral side may experience hypotrophy/atrophy if the crossbite is not corrected.

Author Contributions: G.V.: Data curation-Writing original draft; A.C.: Methodology-Validation; M.G.P.: Project Administartion-Validation; M.C.M.: Investigation-Resources; M.R.A.: MethodologyVisualization; G.P.: Visualization-Software. G.C.: Validation and Writing, Review, Editing. All authors have read and agreed to the published version of the manuscript.

Funding: No Funding.

Institutional Review Board Statement: Ethics committee approval: “Morphological and molecular evaluation of the masseter muscle in orthognathic surgical patients" approved on 18 June 2018 protocol n.0063261, document number CS2/372 of "Comitato Etico Interaziendale A.O.U. Città della Salute e della Scienza di Torino-A.O. Ordine Mauriziano-A.S.L. Città di Torino".

Informed Consent Statement: Informed consent was obtained from all subjects involved in the study.

Data Availability Statement: Data is contained within the article.

Conflicts of Interest: The authors declare no conflict of interest. 


\section{References}

1. Lopatienè, K.; Trumpytè, K. Relationship between unilateral posterior crossbite and mandibular asymmetry during late adolescence. Stomatologija 2018, 20, 90-95. [PubMed]

2. Brizuela, M.; Palla, A.; Dilip, K.N. Posterior Crossbite Review. StatPearls [Internet]; StatPearls Publishing: Treasure Island, FL, USA, 2021.

3. Piancino, M.G.; Farina, D.; Talpone, F.; Merlo, A.; Bracco, P. Muscular activation during reverse and non-reverse chewing cycles in unilateral posterior crossbite. Eur. J. Oral Sci. 2009, 117, 122-128. [CrossRef] [PubMed]

4. Piancino, M.G.; Comino, E.; Talpone, F.; Vallelonga, T.; Frongia, G.; Bracco, P. Reverse sequencing chewing patterns evaluation in anterior versus posterior unilateral crossbite patients. Eur. J. Orthod. 2012, 34, 536-541. [CrossRef] [PubMed]

5. Lombardi de Farias, B.U.; Gonçalves Bianchini, E.M.; De Paiva, B.; Neto, J. Muscular activity in class III dentofacial deformity. Cranio 2013, 31, 181-189. [CrossRef] [PubMed]

6. Bani, D.; Bani, T.; Bergamini, M. Morphologic and Biochemical Changes of the Masseter Muscles Induced by Occlusal Wear: Studies in a Rat Model. J. Dent. Res. 1999, 78, 1735-1744. [CrossRef]

7. Cutroneo, G.; Piancino, M.G.; Ramieri, G.; Bracco, P.; Vita, G.; Isola, G.; Vermiglio, G.; Favaloro, A.; Anastasi, G.; Trimarchi, F. Expression of muscle-specific integrins in masseter muscle fibers during malocclusion disease. Int. J. Mol. Med. 2012, 30, 235-242. [CrossRef]

8. Cutroneo, G.; Vermiglio, G.; Centofanti, A.; Rizzo, G.; Runci, M.; Favaloro, A.; Piancino, M.; Bracco, P.; Ramieri, G.; Bianchi, F.; et al. Morphofunctional compensation of masseter muscles in unilateral posterior crossbite patients. Eur. J. Histochem. 2016, 60, 2605. [CrossRef]

9. Arco, A.M.; Favaloro, A.; Gioffrè, M.; Santoro, G.; Speciale, F.; Vermiglio, G.; Cutroneo, G. Sarcoglycans in the Normal and Pathological Breast Tissue of Humans: An Immunohistochemical and Molecular Study. Cells Tissues Organs 2012, 195, 550-562. [CrossRef]

10. Cutroneo, G.; Centofanti, A.; Speciale, F.; Rizzo, G.; Favaloro, A.; Santoro, G.; Bruschetta, D.; Milardi, D.; Micali, A.; DI Mauro, D.; et al. Sarcoglycan complex in masseter and sternocleidomastoid muscles of baboons: An immunohistochemical study. Eur. J. Histochem. 2015, 59, 2509. [CrossRef]

11. Vermiglio, G.; Centofanti, A.; Ramieri, G.; Tepedino, M.; Anastasi, M.R.; Micali, A.; Arco, A.; Piancino, M. Immunofluorescence Evaluation of Myf5 and MyoD in Masseter Muscle of Unilateral Posterior Crossbite Patients. J. Funct. Morphol. Kinesiol. 2020, 5, 80. [CrossRef]

12. Alarcón, J.A.; Martín, C.; Palma, J.C. Effect of unilateral posterior crossbite on the electromyographic activity of human masticatory muscles. Am. J. Orthod. Dentofac. Orthop. 2000, 118, 328-334. [CrossRef] [PubMed]

13. Guerra, C.D.S.; Pereira, Y.C.L.; Issa, J.P.M.; Luiz, K.G.; Guimarães, E.A.D.B.; Gerlach, R.F.; Iyomasa, M.M. Histological, Histochemical, and Protein Changes after Induced Malocclusion by Occlusion Alteration of Wistar Rats. BioMed Res. Int. 2014, 2014, 1-10. [CrossRef]

14. Ervasti, J.M.; Ohlendieck, K.; Kahl, S.D.; Gaver, M.G.; Campbell, K.P. Deficiency of a glycoprotein component of the dystrophin complex in dystrophic muscle. Nature 1990, 345, 315-319. [CrossRef] [PubMed]

15. Yoshida, M.; Ozawa, E. Glycoprotein complex anchoring dystrophin to sarcolemma. J. Biochem. 1990, 108, 748-752. [CrossRef] [PubMed]

16. Ervasti, J.M.; Campbell, K.M. A role for dystrophin-glyco-protein complex as a transmembrane linker between laminin and actin. J. Cell Biol. 1993, 122, 809-823. [CrossRef] [PubMed]

17. Yoshida, M.; Suzuki, A.; Yamamoto, H.; Noguchi, S.; Mizuno, Y.; Ozawa, E. Dissociation of the complex of dystrophin and its asso-ci-ated proteins into several unique groups by n-octyl $\beta$-D-glucoside. Eur. J. Biochem. 1994, 222, 1055-1061. [CrossRef]

18. Militi, A.; Cutroneo, G.; Favaloro, A.; Matarese, G.; Di Mauro, D.; Lauritano, F.; Centofanti, A.; Cervino, G.; Nicita, F.; Bra-manti, A. An immunofluorescence study on VEGF and extracellular matrix proteins in human periodontal ligament during tooth movement. Heliyon 2019, 5, e02572. [CrossRef]

19. De Ponte, F.S.; Favaloro, A.; Siniscalchi, E.N.; Centofanti, A.; Runci, M.; Cutroneo, G.; Catalfamo, L. Sarcoglycans and integrins in bisphosphonate treatment: Immunohistochemical and scanning electron microscopy study. Oncol. Rep. 2013, 30, 2639-2646. [CrossRef]

20. De Ponte, F.S.; Catalfamo, L.; Micali, G.; Runci, M.; Cutroneo, G.; Vermiglio, G.; Centofanti, A.; Rizzo, G. Effect of bisphosphonates on the mandibular bone and gingival epithelium of rats without tooth extraction. Exp. Ther. Med. 2016, 11, 1678-1684. [CrossRef]

21. De Ponte, F.S.; Cutroneo, G.; Falzea, G.; Rizzo, G.; Catalfamo, L.; Favaloro, A.; Vermiglio, G.; Runci, M.; Centofanti, A.; Anastasi, G. Histochemical and morphological aspects of fresh frozen bone: A preliminary study. Eur. J. Histochem. 2016, 60, 2642. [CrossRef]

22. Huang, C.C.; Hall, D.H.; Hedgecock, E.M.; Kao, G.; Karantza, V.; Vogel, B.E.; Hutter, H.; Chisholm, A.D.; Yurchenco, P.D.; Wadsworth, W.G. Laminin alpha subunits and their role in C. elegans development. Development 2003, 130, 3343-3358. [CrossRef] [PubMed]

23. Colognato, H.; Winkelmann, D.A.; Yurchenco, P.D. Laminin Polymerization Induces a Receptor-Cytoskeleton Network. J. Cell Biol. 1999, 145, 619-631. [CrossRef] [PubMed]

24. Mendias, C.L.; Schwartz, A.J.; Grekin, J.A.; Gumucio, J.P.; Sugg, K.B. Changes in muscle fiber contractility and extracellular matrix production during skeletal muscle hypertrophy. J. Appl. Physiol. 2017, 122, 571-579. [CrossRef] [PubMed] 
25. Mackey, A.L.; Donnelly, A.E.; Turpeenniemi-Hujanen, T.; Roper, H.P. Skeletal muscle collagen content in humans after high-force eccentric contractions. J. Appl. Physiol. 2004, 97, 197-203. [CrossRef]

26. Roach, D.; Fitridge, R.; Laws, P.; Millard, S.; Varelias, A.; Cowled, P. Up-regulation of MMP-2 and MMP-9 Leads to Degradation of Type IV Collagen During Skeletal Muscle Reperfusion Injury; Protection by the MMP Inhibitor, Doxycycline. Eur. J. Vasc. Endovasc. Surg. 2002, 23, 260-269. [CrossRef]

27. Singh, A.; Nelson-Moon, Z.; Thomas, G.; Hunt, N.; Lewis, M. Identification of matrix metalloproteinases and their tissue inhibitors type 1 and 2 in human masseter muscle. Arch. Oral Biol. 2000, 45, 431-440. [CrossRef]

28. Tippett, H.L.; Dodgson, L.K.; Hunt, N.P.; Lewis, M.P. Indices of extracellular matrix turnover in human masseter muscles as markers of craniofacial form-A preliminary study. Eur. J. Orthod. 2008, 30, 217-225. [CrossRef]

29. Dahiya, S.; Bhatnagar, S.; Hindi, S.M.; Jiang, C.; Paul, P.K.; Kuang, S.; Kumar, A. Elevated levels of active-matrix metalloproteinase-9 cause hypertrophy in skeletal muscle of normal and dystrophin-deficient mdx mice. Hum. Mol. Genet. 2011, 15, 4345-4359. [CrossRef]

30. Ren, X.; Lamb, G.D.; Murphy, R.M. Distribution and activation of matrix metalloproteinase-2 in skeletal muscle fibers. Am. J. Physiol. Physiol. 2019, 317, C613-C625. [CrossRef]

31. Skittone, L.K.; Liu, X.; Tseng, A.; Kim, H.T. Matrix metalloproteinase-2 expression and promoter/enhancer activity in skeletal muscle atrophy. J. Orthop. Res. 2008, 26, 357-363. [CrossRef]

32. Liu, X.; Manzano, G.; Lovett, D.H.; Kim, H.T. Role of AP-1 and RE-1 binding sites in matrix metalloproteinase-2 transcrip-tional regulation in skeletal muscle atrophy. Biochem. Biophys. Res. Commun. 2010. [CrossRef]

33. Liu, X. Emerging Ideas: Matrix Metalloproteinase-2 in Muscle Atrophy. Clin. Orthop. Relat. Res. 2011, 469, 1797-1799. [CrossRef] [PubMed] 